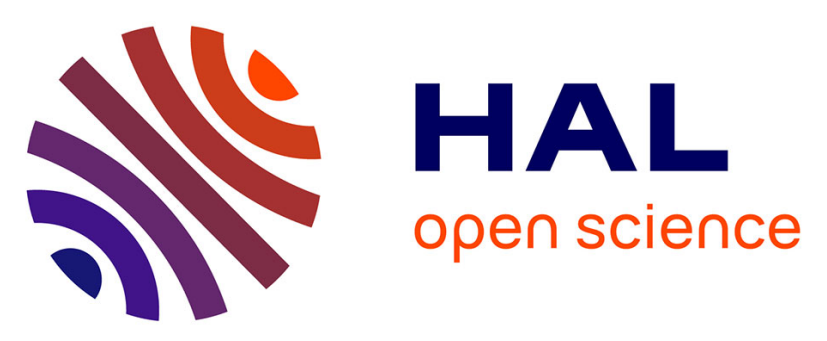

\title{
Left atrial function, a new predictor of response to cardiac resynchronization therapy?
}

\author{
Damien Feneon, Albin Behaghel, Anne Bernard, Maxime Fournet, Philippe \\ Mabo, J-Claude Daubert, Christophe Leclercq, Erwan Donal
}

\section{To cite this version:}

Damien Feneon, Albin Behaghel, Anne Bernard, Maxime Fournet, Philippe Mabo, et al.. Left atrial function, a new predictor of response to cardiac resynchronization therapy?: Left atrium and resynchronization. Heart Rhythm, 2015, 12 (8), pp.1800-1806. 10.1016/j.hrthm.2015.04.021 . inserm01172667

\section{HAL Id: inserm-01172667 https://www.hal.inserm.fr/inserm-01172667}

Submitted on 7 Jul 2015

HAL is a multi-disciplinary open access archive for the deposit and dissemination of scientific research documents, whether they are published or not. The documents may come from teaching and research institutions in France or abroad, or from public or private research centers.
L'archive ouverte pluridisciplinaire HAL, est destinée au dépôt et à la diffusion de documents scientifiques de niveau recherche, publiés ou non, émanant des établissements d'enseignement et de recherche français ou étrangers, des laboratoires publics ou privés. 
Left atrium function, a new predictor of response to cardiac resynchronization therapy?

Running Title: Left atrium and resynchronization

Damien FENEON*1,2, MD, Albin BEHAGHEL ${ }^{* 1,2}, \mathrm{MD}$, Anne BERNARD ${ }^{2,3}, \mathrm{MD}, \mathrm{PhD}$,

Maxime FOURNET ${ }^{1,2}$, MD, Philippe $\mathrm{MABO}^{1,2}$, MD, J-Claude DAUBERT ${ }^{1,2}$, MD,

Christophe LECLERCQ ${ }^{1,2}, \mathrm{MD}, \mathrm{PhD}$, Erwan DONAL ${ }^{1,2}, \mathrm{MD}, \mathrm{PhD}$.

*: The first two authors contributed equally to this work

From:

${ }^{1}$ Cardiologie et CIC-IT U 804, Centre Hospitalier Universitaire de Rennes, France

${ }^{2}$ LTSI, Université Rennes 1, INSERM 1099, Rennes, France

${ }^{3}$ Service de Cardiologie, CHU Tours, F-37000, France

Word Count: 4877

\section{Correspondence}

Erwan Donal, MD, $\mathrm{PhD}$,

Service de Cardiologie - Hôpital Pontchaillou - CHU Rennes

F-35033 Rennes, France

erwan.donal@chu-rennes.fr

Fax: $33299282510 \quad$ Tel.: 33299282510

\section{Conflict of interest: none}




\section{ACCEPTED MANUSCRIPT}

ABSTRACT:

Background: Cardiac resynchronization therapy (CRT) improves left ventricular (LV) function and induces LV remodeling, and it is an established therapy for advanced heart failure with prolonged QRS duration. One third of patients will not benefit from this invasive therapy.

Objective: We sought to evaluate whether left atrial (LA) strain imaging ( $(\varepsilon)$ parameters could help in predicting the response in terms of LV reverse remodeling after CRT.

Methods: A total of 79 patients who underwent CRT were evaluated with echography before implantation. LA function and LV function were assessed with M-mode, two-dimensional echocardiography, Doppler, tissue Doppler velocity and $\varepsilon$. LV reverse remodeling was defined as a reduction in LV end-systolic volume of $>15 \%$.

Results : At 6 months, 54 (68\%) patients were responders to CRT. In multivariable logistic regression, LA systolic peak of strain rate $(\mathrm{SRA})(\mathrm{OR}=10.5 ; 95 \% \mathrm{CI}=1.76-62.1, \mathrm{p}=0.01)$, left bundle branch block $(\mathrm{OR}=6.8,95 \% \mathrm{CI}=1.06-43.9, \mathrm{p}=0.04)$, ischemic cardiomyopathy $(\mathrm{OR}=3.93,95 \% \mathrm{CI}=1.07-14.4, \mathrm{p}=0.04)$ and $\mathrm{LV}$ pre-ejection index $(\mathrm{OR}=1.03,95 \% \mathrm{CI}=1.01-$ 1.05, $\mathrm{p}=0.01$ ) were associated with CRT response. With an SRA cut-off of $-0.75 \%$, the negative predictive value for predicting CRT response was 0.62 .

Conclusion: The present study demonstrated that it could be enormously relevant to assess LA function before CRT. SRA appeared to be a good predictor of CRT response. Integrating this LA function analysis into the multivariable assessment of patient candidates for CRT should be considered.

Key words: cardiac resynchronization therapy, left atrial function, strain imaging, echocardiography 
List of the abbreviations:

CRT: cardiac resynchronization therapy

LA: left atrial

LV: left ventricular

EF: ejection fraction

AV: atrio ventricular

DFT: diastolic filling time

$\mathrm{V}$ : volume

LVPEI: LV pre-ejection interval

IVMD: inter-ventricular mechanical delay

\section{Introduction}

Echocardiography plays an important role in patient assessment before cardiac resynchronization therapy (CRT), and it can monitor many of the mechanical effects of CRT in heart failure patients ${ }^{12} 3$. Encouraged by the highly variable individual response observed in the major CRT trials, echocardiography-based measurements of mechanical dyssynchrony have been extensively investigated, with the aim of improving the prediction of response to CRT $^{2} 4567$. There has been no consensus on mechanical dyssynchrony analysis before CRT implantation because larger studies have been somewhat disappointing ${ }^{189}$. According to the current literature, it seems that one can still hope to predict the response to CRT with mechanical dyssynchrony analysis, but the negative predictive value of all of the proposed approaches remains low ${ }^{10}$.

Apart from mechanical dyssynchrony, other morphologic parameters have been tested to predict CRT response. Leyva et $\mathrm{al}^{11}$ considered left ventricle fibrosis assessed by cardiac magnetic resonance. Damy et $\mathrm{al}^{12}$ showed the prognostic value of right ventricle function. 


\section{ACCEPTED MANUSCRIPT}

There have also been a few studies examining the relationship of the left atrium (LA) with CRT 13 14. Until now, diastolic function, with the exception of atrio-ventricular dyssynchrony $^{15}$, has not been expected to be reported when assessing a patient before CRT implantation. Nevertheless, the value of LA volume as a strong prognostic marker has largely been demonstrated in many fields, including systolic heart failure ${ }^{16}$. Furthermore, we can easily assess the size of the LA, as well as its function to some extent. Very promising observations have been made in the field of $\mathrm{CRT}^{17}$, including a study performed in our institution $^{14}$, and even more observations have been made in the field of valvular heart disease

18. Speckle tracking echocardiography is a novel method for angle-independent and objective quantification of myocardial deformation from standard bidimensional datasets; speckle tracking has the advantages of being angle-independent and being weakly affected by reverberations, side lobes and dropout artifacts. Speckle tracking echocardiography has recently evolved, and, by enabling the quantification of longitudinal myocardial LAdeformation dynamics, it was recently proposed as an alternative approach for the estimation of LV filling pressure. In fact, the LA is exposed to the cumulative effects of filling pressures over time and could, therefore, provide a more sensitive and likely more relevant expression of the severity of LV (and heart as a whole) dysfunction than measurement of the characteristics of the left ventricle.

Therefore, we sought to examine the ability of LA function characteristics to predict response to treatment in a typical population of patients referred for CRT.

\section{Methods}

\section{Patient population}

Between April 2007 and February 2012, consecutive patients scheduled to undergo implantation of CRT systems at the Rennes University medical center were prospectively 


\section{ACCEPTED MANUSCRIPT}

included in this study. The goal was to assess the feasibility and value of using LA strain (as a relevant manner for assessing LA function), in terms of predicting LV-reverse remodeling. The inclusion criteria were: 1) New York Heart Association (NYHA) functional class II-IV, despite optimal medical therapy; 2) an $\mathrm{LVEF} \leq 35 \%$; 3) a stable sinus rhythm, 4) a QRS duration $\geq 120 \mathrm{~ms}$ on 12-lead electrocardiography; and 5) no previous pacemaker or cardioverter defibrillator implantation. Patients with atrial fibrillation were excluded. Heart disease was considered ischemic if a $50 \%$ stenosis was observed in $\geq 1$ major epicardial coronary artery or if the patient had a history of myocardial infarction or prior coronary revascularization. The patients were followed up at 6 months after implantation of the device. No patients were lost to follow-up, and all of them returned to the laboratory to meet the requirements of the study.

Responders were defined as having a $\geq 15 \%$ decrease in left ventricular end-systolic volume at the 6-month follow-up, compared with baseline. This measurement was chosen because it was the endpoint chosen in most of the studies in this field ${ }^{19}$.

This study was performed in accordance with the principles outlined in the Declaration of Helsinki on research in human subjects and with the procedures of the Rennes University Hospital Medical Ethics Committee (usual care). The study was approved by a national review committee (no. CNIL 0507317b). The patients provided their informed consent.

\section{Transthoracic echocardiography}

Each patient was placed in the left lateral decubitus position and was assessed using echocardiography with either the Vivid 7 or Vivid e 9 ultrasound system (GE Medical Systems, Horten, Norway), equipped with 2.5-MHz transducers. LV volume and LA volume (LAV) were quantified according to the recommendations of the American Society of Echocardiography ${ }^{20}$. LAVs were calculated using the apical 4- and 2-chamber area-length 


\section{ACCEPTED MANUSCRIPT}

method, and they were subsequently indexed to body surface area (LAV index [LAVI]) as described earlier ${ }^{21}$. Trans-mitral flow (E wave and deceleration time) and mitral annular tissue Doppler $\left(E^{\prime}\right.$ and $\left.S^{\prime}\right)$ velocities were measured. The Doppler value recorded was the mean of three beats. All of the measurements were obtained according to recommendations of chamber quantification $^{20}$ and diastolic function assessment ${ }^{22}$. Diastolic filling time (DFT)/RR interval ratio was used to characterize atrioventricular (AV) dyssynchrony in the left heart. AV dyssynchrony was defined as DFT/RR $<40 \%{ }^{15}$. LV pre-ejection interval (LVPEI), and IVMD (inter-ventricular mechanical delay) were used to characterize interventricular dyssynchrony ${ }^{15}$.

\section{Left atrial deformation imaging indices}

Three consecutive cardiac cycles were recorded and averaged, and the frame rate was set to 60 to 80 frames/sec. The analysis was performed offline using customized software (EchoPAC PC BT12; GE healthcare, Horten, Norway). The LA endocardial border was manually traced on the apical four-chamber view. After manual adjustment of a region of interest covering the full thickness of the myocardium, the software divided the left atrium into six segments and automatically scored the segmental tracking quality. The software rejected segments with inadequate image quality and excluded them from the analysis. Longitudinal strain curves were generated for each of the 6 LA segments in the four chambers. Global peak LA longitudinal strain during ventricular systole (Es) was then measured by averaging the values obtained from the 6 LA segments. The same tracing method was used to calculate the strain rate and to analyze the LA systolic peak of strain rate (SRA) ${ }^{23}$. A cardiologist with a level 3 in echocardiography, who was unaware of the patients' information, analyzed all of the echocardiographic values (figure 1). 


\section{Observer variability}

Twenty studies were randomly selected for inter-observer and intra-observer variability. Systolic strain and the strain rate from the left atrium apical four-chamber view were remeasured by the same observer and by a second independent observer based on the digital data, using an offline system.

\section{Statistical analysis}

Continuous variables are presented as means (SDs) or medians (IQRs) in cases of skewness. Categorical data are summarized as frequencies and percentages. Differences in baseline characteristics between the two groups (responders and non-responders) were analyzed with Student's t-test, the Mann-Whitney test, the Chi-square test or Fisher's exact test, as appropriate. Correlations between variables were determined with Pearson's product moment correlation analysis. Multivariate logistic regression analysis was used to assess relationships between the different variables and CRT response. We included in the multivariable analysis all of the variables with $\mathrm{p}<0.05$ in univariate analysis, after removing correlated variables (Pearson's coefficient $>0.70$ ). Stepwise forward/backward selection was performed according to the Akaike Information Criterion. Optimal cut-off values of LA parameters to predict response to CRT were determined by ROC curve analysis. The optimal cut-off value was defined as that providing maximal accuracy to distinguish between responders and nonresponders. A p value $<0.05$ was considered statistically significant.

All of the statistical analyses were performed with the software package R (R Foundation for Statistical Computing, Vienna, Austria; URL: http://www.R-project.org/). 


\section{ACCEPTED MANUSCRIPT}

\section{Results}

\section{Study population and Clinical Status}

A total of 79 patients, of 102 consecutive patients (77\%), were considered based on the recordings of their echocardiography, providing images allowing for the measurement of $\varepsilon s$ and SR-A. Their baseline demographic, clinical, echocardiographic characteristics are presented in table 1. The disease etiology was ischemic in $25 \%$ of the patients. More than $90 \%$ of patients were treated with a beta-adrenergic blocker and an angiotensin-converting enzyme inhibitor or angiotensin II receptor blocker at the highest tolerated doses. At 6 months, $68 \%$ of the patients were responders to CRT.

\section{Measurement of Reproducibility}

For $\varepsilon s$, the ICCs were 0.96 and 0.90 , respectively, for inter- and intra-observer agreement, and for SRA, the ICCs were 0.83 and 0.78 , respectively. The measurements of $\varepsilon$ S and SRA showed good reproducibility, with intra-observer and inter-observer variations similar to those reported in the literature (table 2). ${ }^{24}$

\section{Uni and multi-variable analysis}

The differences between basal clinical and echocardiographic parameters for the population and according to CRT response are shown in table 1 . All of the parameters with a $p<0.05$ in univariate logistic regression were entered into a multivariable logistic regression analysis. $\varepsilon s$ and SRA were strongly correlated (Pearson's $r=0.81$ ) and could not be analyzed together, so two multivariate logistic regression analyses were performed. The results are shown in table 3. In multivariate analysis, the following were associated with CRT response: SRA $(O R=4.7$, $\mathrm{p}=0.02), \operatorname{LBBB}(\mathrm{OR}=4.5, \mathrm{p}=0.05)$, non-ischemic cardiomyopathy $(\mathrm{OR}=3.73, \mathrm{p}=0.04)$, LVPEI $(\mathrm{OR}=1.02, \mathrm{p}=0.014)$ and $\varepsilon s(\mathrm{OR}=1.12, \mathrm{p}=0.04)$. 


\section{ROC analysis}

The ROC for SRA is shown in Figure 2

. Table 4 shows the accuracy of testing according to different cut-off value. The best accuracy (0.77) was obtained with an SRA value of $-0.75 \%$. The best negative predictive value (NPV) was 0.62 in our population (64\% of responders) and was obtained with an SRA value of $0.75 \%$. The best Predictive Positive Value (PPV) in our population is 0.89 and was obtained with a SRA value of $-1 \%$. Regarding LVPEI, the best cut-off in our population was $125 \mathrm{~ms}$ (140 ms in the literature $\left.{ }^{15}\right)$. With this value, the accuracy was 0.76 , and the PPV and NPV were, respectively, 0.86 and 0.60 . If we associated LVPEI $>125 \mathrm{~ms}$ with $\mathrm{SRA}<0.75 \%$, the PPV to predict CRT was 0.97 , the NPV was then 0.53 , and the accuracy was 0.72 .

\section{Discussion}

The present study demonstrated that it could be quite relevant to assess LA function and, in particular, to consider LA strain data for predicting CRT response and non-response.

LA has been proposed as being analogous in heart conditions to HbAlc in diabetes. . Nevertheless, very few investigations have been published that have examined the promising role of LA strain imaging in better understanding and perhaps in predicting the response or non-response to CRT. D'Andrea et $\mathrm{al}^{13}$ reported that LA strain could be measured in candidates for CRT. We previously observed significant reverse remodeling in LA functional, structural, and anatomic characteristics after successful CRT. LA reverse remodeling was correlated with baseline LA volume ${ }^{14}$. Yu et al ${ }^{17}$ showed that responders to CRT had improvements in contraction velocity in both the left and right atria, as well as improvement in LA reverse remodeling with a reduction in the LA size. LA reverse remodeling was also more frequent in patients with LV reverse remodeling ${ }^{14}$. 


\section{ACCEPTED MANUSCRIPT}

The LA has multiple functions: it acts as a reservoir for blood during ventricular systole (atrial compliance), as a conduit for the passage of blood from the pulmonary veins to the left ventricle in early diastole (passive emptying) and as a contractile chamber to augment left ventricular filling in late diastole (active atrial contraction). LA size ${ }^{1623}$ and function ${ }^{25}$ have been used as prognostic markers for adverse cardiovascular events in numerous clinical settings.

Nevertheless, there is currently no accepted 'gold standard' for evaluating LA function, despite very promising studies. $\varepsilon$ and SR techniques have enabled the evaluation of atrial function throughout the cardiac cycle, thereby facilitating the measurement of phasic atrial function. $\varepsilon S$ and SRA serve as measurements of LA compliance during the reservoir phase, with early diastolic SR a measurement of passive emptying during the conduit phase and late diastolic SR a measurement of active atrial contraction ()$^{23}$. These parameters seem correlated with, or at least influenced by, atrial fibrosis. Kuppahaly et al ${ }^{26}$ showed that there were correlations of LA fibrosis detected by delayed-enhancement MRI with LA $\varepsilon$ and SR. Cameli et $\mathrm{al}^{27}$ showed, in patients with severe MR, a close, negative correlation between measured $\varepsilon \mathrm{S}$ and histological LA fibrosis grade. In a previous study, atrial fibrosis was strongly associated with prognosis in heart failure ${ }^{28}$. We could hypothesize that severe cardiomyopathy, with a fibrotic and not a deforming atrium, is not an adequate candidate for CRT. SRA and $\varepsilon$, as surrogate markers for atrial fibrosis, could help to define this group of cardiomyopathies, which would be too greatly remodeled to expect any reverse remodeling with any type of treatment. That remains a hypothesis and further prospective multi-center validation studies are required. The respective value of strain and strain rate is requiring the transfer of our monocentric observations to a prospective multicenter validation.

Of course, LA function would have to be considered, in addition to other critical parameters.

First, LBBB was a strong predictor of response to CRT in our study. The enrollment of 


\section{ACCEPTED MANUSCRIPT}

patients occurred between 2010 and 2011, and the guidelines were more focused on QRS

width than on QRS morphology, as they now are ${ }^{9}$. This focus emphasized the importance of morphology over width. Ischemic cardiomyopathy has a lower response to CRT, as shown earlier ${ }^{19}$. Additionally, the original goal of CRT was mitigation of mechanical dyssynchrony between the right and left ventricles, with a view toward improving hemodynamic function. Contraction of some segments might be so delayed that they end past the onset of ventricular filling and after the end of ejection, causing intra-ventricular asynchrony due to the coexistence of systole and diastole. LVPEI was used and validated to assess this mechanical dyssynchrony ${ }^{15}$. In our study, in multivariable analysis, LVPEI was one of the parameters that predicted response to CRT. It is a simple index and one that has not been discredited in prospective trials ${ }^{1}$. The present study focused on the value of LA function and particularly LA strain parameters for understanding the response to CRT.

\section{Limitations}

This was a mechanistic study that had as its only aim providing new knowledge about the mechanisms implicated in the response to CRT. We focused on the LA because LA strain and $\mathcal{E}$ seemed perhaps more predictive of the response to CRT than the usual LV parameters that have been extensively studied previously. We must acknowledge that we only focused on the LA and not on the two atrial functions or on synchronicity. The far location of the atrium, the reduced signal-to-noise ratio, the thin atrial wall and the presence of the appendage and pulmonary veins make strain imaging of left atrium more difficult and time consuming than for the $\mathrm{LV}^{23}$. Nevertheless, with dedicated attention (focusing on the atrium) and with the improvements in software proposed year after year, the application of speckle tracking in 


\section{ACCEPTED MANUSCRIPT}

daily clinical routine is likely not a dream but almost a reality, provided its incremental value is confirmed in further studies.

\section{Conclusion}

The present study demonstrated that it could be relevant to assess LA function before CRT. SRA appeared to be a good predictor of CRT response. Integrating this LA function analysis into the multivariable assessment of patients who are candidates for CRT should be considered.

Acknowledgments: we obtained a grant from "la fondation de l'avenir" for conducting this work and we want to thanks Marie Guinoiseau, Valérie Le Moal for their impressive help all over the study. 
1. Chung ES, Leon AR, Tavazzi L, et al.: Results of the Predictors of Response to CRT (PROSPECT) Trial. Circulation 2008; 117:2608-2616.

2. Stankovic I, Aarones M, Smith H-J, Voros G, Kongsgaard E, Neskovic AN, Willems R, Aakhus S, Voigt J-U: Dynamic relationship of left-ventricular dyssynchrony and contractile reserve in patients undergoing cardiac resynchronization therapy. Eur Heart J $2014 ; 35$.

3. Donal E, Lund L, Linde C, Daubert J-C: Is cardiac resynchronization therapy an option in heart failure patients with preserved ejection fraction? Justification for the ongoing KaRen project. Arch Cardiovasc Dis 2010; 103:404-410.

4. Lumens J, Leenders GE, Cramer MJ, De Boeck BWL, Doevendans PA, Prinzen FW, Delhaas T: Mechanistic Evaluation of Echocardiographic Dyssynchrony Indices: Patient Data Combined With Multiscale Computer Simulations. Circ Cardiovasc Imaging 2012; 5:491-499.

5. Risum N, Williams ES, Khouri MG, Jackson KP, Olsen NT, Jons C, Storm KS, Velazquez EJ, Kisslo J, Bruun NE, Sogaard P: Mechanical dyssynchrony evaluated by tissue Doppler cross-correlation analysis is associated with long-term survival in patients after cardiac resynchronization therapy. Eur Heart J 2013; 34:48-56.

6. Gorcsan J, Oyenuga O, Habib PJ, Tanaka H, Adelstein EC, Hara H, McNamara DM, Saba S: Relationship of Echocardiographic Dyssynchrony to Long-Term Survival After Cardiac Resynchronization Therapy. Circulation 2010; 122:1910-1918.

7. Brunet-Bernard A, Maréchaux S, Fauchier L, Guiot A, Fournet M, Reynaud A, Schnell F, Leclercq C, Mabo P, Donal E: Combined Score Using Clinical, Electrocardiographic, and Echocardiographic Parameters to Predict Left Ventricular Remodeling in Patients Having Had Cardiac Resynchronization Therapy Six Months Earlier. Am J Cardiol 2014; 113:2045-2051.

8. Ruschitzka F, Abraham WT, Singh JP, et al.: Cardiac-Resynchronization Therapy in Heart Failure with a Narrow QRS Complex. N Engl J Med 2013; 369:1395-1405.

9. Authors/Task Force Members, McMurray JJV, Adamopoulos S, et al.: ESC Guidelines for the diagnosis and treatment of acute and chronic heart failure 2012: The Task Force for the Diagnosis and Treatment of Acute and Chronic Heart Failure 2012 of the European Society of Cardiology. Developed in collaboration with the Heart Failure Association (HFA) of the ESC. Eur Heart J 2012; 33:1787-1847.

10. Maréchaux S, Guiot A, Castel AL, Guyomar Y, Semichon M, Delelis F, Heuls S, Ennezat P-V, Graux P, Tribouilloy C: Relationship between Two-Dimensional SpeckleTracking Septal Strain and Response to Cardiac Resynchronization Therapy in Patients with Left Ventricular Dysfunction and Left Bundle Branch Block: A Prospective Pilot Study. J Am Soc Echocardiogr 2014; 27:501-511.

11. Leyva F, Taylor RJ, Foley PWX, Umar F, Mulligan LJ, Patel K, Stegemann B, Haddad T, Smith REA, Prasad SK: Left Ventricular Midwall Fibrosis as a Predictor of Mortality and Morbidity After Cardiac Resynchronization Therapy in Patients With Nonischemic Cardiomyopathy. J Am Coll Cardiol 2012; 60:1659-1667. 


\section{ACCEPTED MANUSCRIPT}

12. Damy T, Ghio S, Rigby AS, Hittinger L, Jacobs S, Leyva F, Delgado JF, Daubert J-C, Gras D, Tavazzi L, Cleland JGF: Interplay Between Right Ventricular Function and Cardiac Resynchronization Therapy. J Am Coll Cardiol 2013; 61:2153-2160.

13. Romano S, Scarafile R, Riegler L, et al.: Different effects of cardiac resynchronization therapy on left atrial function in patients with either idiopathic or ischaemic dilated cardiomyopathy: a two-dimensional speckle strain study. Eur Heart J 2007; 28:27382748.

14. Donal E, Tan K, Leclercq C, Ollivier R, Derumeaux G, Bernard M, de Place C, Mabo P, Daubert J-C: Left Atrial Reverse Remodeling and Cardiac Resynchronization Therapy for Chronic Heart Failure Patients in Sinus Rhythm. J Am Soc Echocardiogr 2009; 22:1152-1158.

15. Cazeau S, Bordachar P, Jauvert G, Lazarus A, Alonso C, Vandrell MC, Mugica J, Ritter P: Echocardiographic modeling of cardiac dyssynchrony before and during multisite stimulation: a prospective study. Pacing Clin Electrophysiol PACE 2003; 26:137-143.

16. Kuperstein R, Goldenberg I, Moss AJ, Solomon S, Bourgoun M, Shah A, McNitt S, Zareba W, Klempfner R: Left Atrial Volume and the Benefit of Cardiac Resynchronization Therapy in the MADIT-CRT Trial. Circ Heart Fail 2014; 7:154-160.

17. Yu C-M, Fang F, Zhang Q, Yip GWK, Li CM, Chan JY-S, Wu L, Fung JW-H: Improvement of Atrial Function and Atrial Reverse Remodeling After Cardiac Resynchronization Therapy for Heart Failure. J Am Coll Cardiol 2007; 50:778-785.

18. O’Connor K, Magne J, Rosca M, Piérard LA, Lancellotti P: Impact of Aortic Valve Stenosis on Left Atrial Phasic Function. Am J Cardiol 2010; 106:1157-1162.

19. Goldenberg I, Moss AJ, Hall WJ, et al.: Predictors of Response to Cardiac Resynchronization Therapy in the Multicenter Automatic Defibrillator Implantation Trial With Cardiac Resynchronization Therapy (MADIT-CRT). Circulation 2011; 124:1527-1536.

20. Lang RM, Bierig M, Devereux RB, et al.: Recommendations for Chamber Quantification: A Report from the American Society of Echocardiography's Guidelines and Standards Committee and the Chamber Quantification Writing Group, Developed in Conjunction with the European Association of Echocardiography, a Branch of the European Society of Cardiology. J Am Soc Echocardiogr 2005; 18:1440-1463.

21. Messika-Zeitoun D, Bellamy M, Avierinos J-F, Breen J, Eusemann C, Rossi A, Behrenbeck T, Scott C, Tajik JA, Enriquez-Sarano M: Left atrial remodelling in mitral regurgitation--methodologic approach, physiological determinants, and outcome implications: a prospective quantitative Doppler-echocardiographic and electron beamcomputed tomographic study. Eur Heart J 2007; 28:1773-1781.

22. Nagueh SF, Appleton CP, Gillebert TC, Marino PN, Oh JK, Smiseth OA, Waggoner AD, Flachskampf FA, Pellikka PA, Evangelisa A: Recommendations for the Evaluation of Left Ventricular Diastolic Function by Echocardiography. Eur J Echocardiogr 2008; 10:165-193.

23. Hoit BD: Left Atrial Size and Function. J Am Coll Cardiol 2014; 63:493-505. 


\section{ACCEPTED MANUSCRIPT}

24. Sirbu C, Herbots L, Dhooge J, Claus P, Marciniak A, Langeland T, Bijnens B, Rademakers F, Sutherland G: Feasibility of strain and strain rate imaging for the assessment of regional left atrial deformation: A study in normal subjects. Eur J Echocardiogr 2006; 7:199-208.

25. Cameli M, Lisi M, Focardi M, Reccia R, Natali BM, Sparla S, Mondillo S: Left Atrial Deformation Analysis by Speckle Tracking Echocardiography for Prediction of Cardiovascular Outcomes. Am J Cardiol 2012; 110:264-269.

26. Kuppahally SS, Akoum N, Burgon NS, et al.: Left Atrial Strain and Strain Rate in Patients With Paroxysmal and Persistent Atrial Fibrillation: Relationship to Left Atrial Structural Remodeling Detected by Delayed-Enhancement MRI. Circ Cardiovasc Imaging 2010; 3:231-239.

27. Cameli M, Lisi M, Righini FM, et al.: Usefulness of Atrial Deformation Analysis to Predict Left Atrial Fibrosis and Endocardial Thickness in Patients Undergoing Mitral Valve Operations for Severe Mitral Regurgitation Secondary to Mitral Valve Prolapse. Am J Cardiol 2013; 111:595-601.

28. Ohtani K, Yutani C, Nagata S, Koretsune Y, Hori M, Kamada T: High prevalence of atrial fibrosis in patients with dilated cardiomyopathy. J Am Coll Cardiol 1995; 25:1162-1169.

\section{Clinical perspectives:}

Cardiac resynchronization therapy (CRT) improves left ventricular (LV) function and induces LV remodeling, and it is an established therapy for advanced heart failure with prolonged QRS duration. One third of patients will not benefit from this invasive therapy. The LA is exposed to the cumulative effects of filling pressures over time and could, therefore, provide a more sensitive and likely relevant expression of the severity of disease and of the risk of nonresponse to a treatment supposed to reverse the remodeling. LA function could be robustly analyzed using speckle tracking and strain data. The present study demonstrated that it could be relevant to assess LA function before CRT. 


\section{ACCEPTED MANUSCRIPT}

Table 1: Baseline Characteristics of Patients

Variable

Men

Age (years old)

Ischemic

cardiomyopathy

Heart rate (beats/min) $66.51(13.03)$

LBBB

QRS (ms)

NYHA (\%):

2

3

$6 \mathrm{~m} \mathrm{WT}(\mathrm{m})$

Septal flash

LV EF

GLS (\%)

LV ED diameter (mm)

IV-delay (ms)

LVPEI (ms)

Ratio diastole/RR (\%)

Ratio E/A

Ratio E/Ea

LA Vi (ml)

TAPSE (mm)

SRA (s-1)

ES (\%)

NT-ProBNP (pg/ml)
All

$(n=79)$

$54(68.4 \%)$

$63.66(10.59)$

$25(31.6 \%)$

$66(83.5 \%)$

$162.4(20)$

$16(23.2 \%)$

$53(76.8 \%)$

414 (103)

$58(73.4 \%)$

$0.27(0.10)$

$7.54(2.58)$

$67(8)$

$43(24)$

$136(34)$

$0.44(0.11)$

$0.89(0.74)$

$12.62(6.56)$

41 (19)

$18(4)$

$-1.00(0.84)$

$13.10(9.75)$

1238 (1882)
CRT non-responders

$(n=25)$

$20(80.0 \%)$

$66.56(10.17)$

$15(60.0 \%)$

$64.72(10.99)$

$16(64.0 \%)$

$158.8(30)$

$163.6(27.5)$

0.086

0.70

$11(23.9 \%)$

$18(78.3 \%)$

$35(76.1 \%)$

$423(73.5)$

$13(52.0 \%)$

$0.30(0.12)$

$7.47(3.13)$

$69(8)$

30 (19)

$117(30)$

$0.49(0.09)$

$1.29(0.89)$

$14.70(8.07)$

$46(13)$

$17(3)$

$-0.65(0.35)$

$10.30(5.9)$

1993 (1447)
$38(18)$

0.04

19 (4)

0.10

$414(121.5) \quad 0.68$

$45(83.3 \%) \quad<0.01$

$0.27(0.9) \quad 0.40$

$7.58(2.31) \quad 0.86$

$66(8) \quad 0.1$

49 (24) $\quad 0.001$

$145(32)<0.001$

$0.42(0.11) \quad 0.01$

$0.76(0.46)<0.01$

$12.12(5.82) \quad 0.03$

$-1.19(0.76)<0.001$

$14.60(9.42)<0.01$

$974(1988) \quad 0.08$

LBBB: Left Bundle Branch Block - 6m WT: 6 Minute Walking Test - LV EF: Left Ventricle Ejection Fraction - GLS: Global Longitudinal Strain - LA Vi: Left Atrium Volume Index - TAPSE: Tricuspid 


\section{ACCEPTED MANUSCRIPT}

Annular Plane Systolic Excursion - SRA: LA Systolic Peak of Strain Rate - es: LA global Longitudinal Strain 


\section{ACCEPTED MANUSCRIPT}

Table 2: Inter- and Intra-observer Reproducibility of LA Strain and Strain Rate Interobserver

Intraobserver

Variable

$$
\text { Relative }
$$

COV ICC

difference

Relative

difference

Es

$0.17+/-1.02$

$10.40 \%$

$0.98(0.94-0.99)$

$-0.14+/-1.30$

$13.30 \% \quad 0.95(0.87-0.98)$

SRA

$0.12+/-0.14 \quad 20.70 \%$

$0.83(0.24-0.95)$

$-0.005+/-0.12$

$16.50 \% \quad 0.78(0.33-0.92)$

COV: Coefficient of Variation - ICC: Intra-Class Coefficient - SRA: LA Systolic Peak of Strain Rate - عs: LA global Longitudinal Strain 


\section{ACCEPTED MANUSCRIPT}

Table 3: Logistic Regression Analysis

Univariable logistic

Variable

Male sex

Age (years old)

Ischemic Cardiomyopathy

Heart Rate (beats/min)

LBBB

QRS (ms)

NYHA (\%):

$6 \mathrm{~m} \mathrm{WT}(\mathrm{m})$

Septal Flash

LV EF

GLS (\%)

LV EDD (mm)

IV-Delay (ms)

LVPEI (ms)

Ratio Diastole/RR (\%)

Ratio E/A

Ratio E/Ea

LA Vi (ml)

TAPSE (mm)

SRA (s-1)

ES (\%)

NT-ProBNP (pg/ml)

OR

$0.96(0.92-1.01)$

$6.6(2.3-18.9)$
Multivariable logistic regression

$$
0.42(0.14-1.31)
$$

0.14

$0.74(0.12-4.4)$

0.74

0.1

$0.95(0.87-1.02)$

0.16

0.0005

$3.73(1.01-13.8)$

0.04

$1.02(0.98-1.05) \quad 0.41$

$$
7.03(1.9-25.9) \quad 0.003
$$

$4.5(0.87-22.9)$

0.05

$1.02(0.99-1.05) \quad 0.22$

$0.61(0.16-2.34) \quad 0.47$

$$
1(0.99-1.01) \quad 0.92
$$

$4.62(1.6-13.3) \quad 0.005$

$2.1(0.5-8.7)$

0.31

$0.06(0.001-87.5) \quad 0.45$

$1.02(0.84-1.23) \quad 0.86$

$0.95(0.90-1.01) \quad 0.11$

$1.04(1.01-1.07) \quad 0.002$

$1.03(1.01-1.05) \quad 0.001$

$1.02(1.0-1.05)$

0.04

$0.0016(0.001-0.243) \quad 0.01$

$0.06(0.001-23.5)$

0.35

$0.67(0.42-1.07) \quad 0.09$

$0.94(0.87-1.01) \quad 0.09$

$0.98(0.95-1.01) \quad 0.20$

$1.11(0.97-1.27) \quad 0.11$

$7.19(2.14-24.1) \quad 0.001$

$4.7(1.26-17.8)$

0.02

$1.14(1.04-1.26) \quad 0.007$

$1.12(1-1.24)$

$0.04 *$

$$
1(1-1) \quad 0.6
$$




\section{ACCEPTED MANUSCRIPT}

LBBB: Left Bundle Branch Block - 6m WT: 6 Minute Walking Test - LV EF: Left Ventricle Ejection Fraction - GLS: Global Longitudinal Strain - LA Vi: Left Atrium Volume Index - TAPSE: Tricuspid Annular Plane Systolic Excursion - SRA: LA Systolic Peak of Strain Rate - es: LA Global Longitudinal Strain

*: This result came from a second multivariate model in which SRA and $\varepsilon$ S were correlated $(\mathrm{r}>0.7)$. 


\section{ACCEPTED MANUSCRIPT}

Table 4: SRA and LVPEI Characteristics to Predict CRT Response

\begin{tabular}{cccccc} 
Variable & Sensitivity & Specificity & $\begin{array}{c}\text { Positive } \\
\text { Predictive } \\
\text { Value }\end{array}$ & $\begin{array}{c}\text { Negative } \\
\text { Predictive } \\
\text { Value }\end{array}$ & Accuracy \\
\hline SRA $<-0.75 \%$ & 0.80 & $0 . .2$ & 0.86 & 0.62 & 0.77 \\
SRA $<-1 \%$ & 0.63 & 0.84 & 0.89 & 0.51 & 0.70 \\
& & & & & 0.76 \\
LVPEI $>125 \mathrm{~ms}$ & 0.78 & 0.72 & 0.86 & 0.60 & 0.63 \\
& & & & & \\
LVPEI $>140 \mathrm{~ms}$ & 0.56 & 0.80 & 0.86 & 0.46 & 0.72 \\
$\begin{array}{l}\text { SRA }<-0.75 \% \& \\
\text { LVPEI }>125 \mathrm{~ms}\end{array}$ & 0.61 & 0.96 & 0.97 & 0.53 &
\end{tabular}




\section{ACCEPTED MANUSCRIPT}

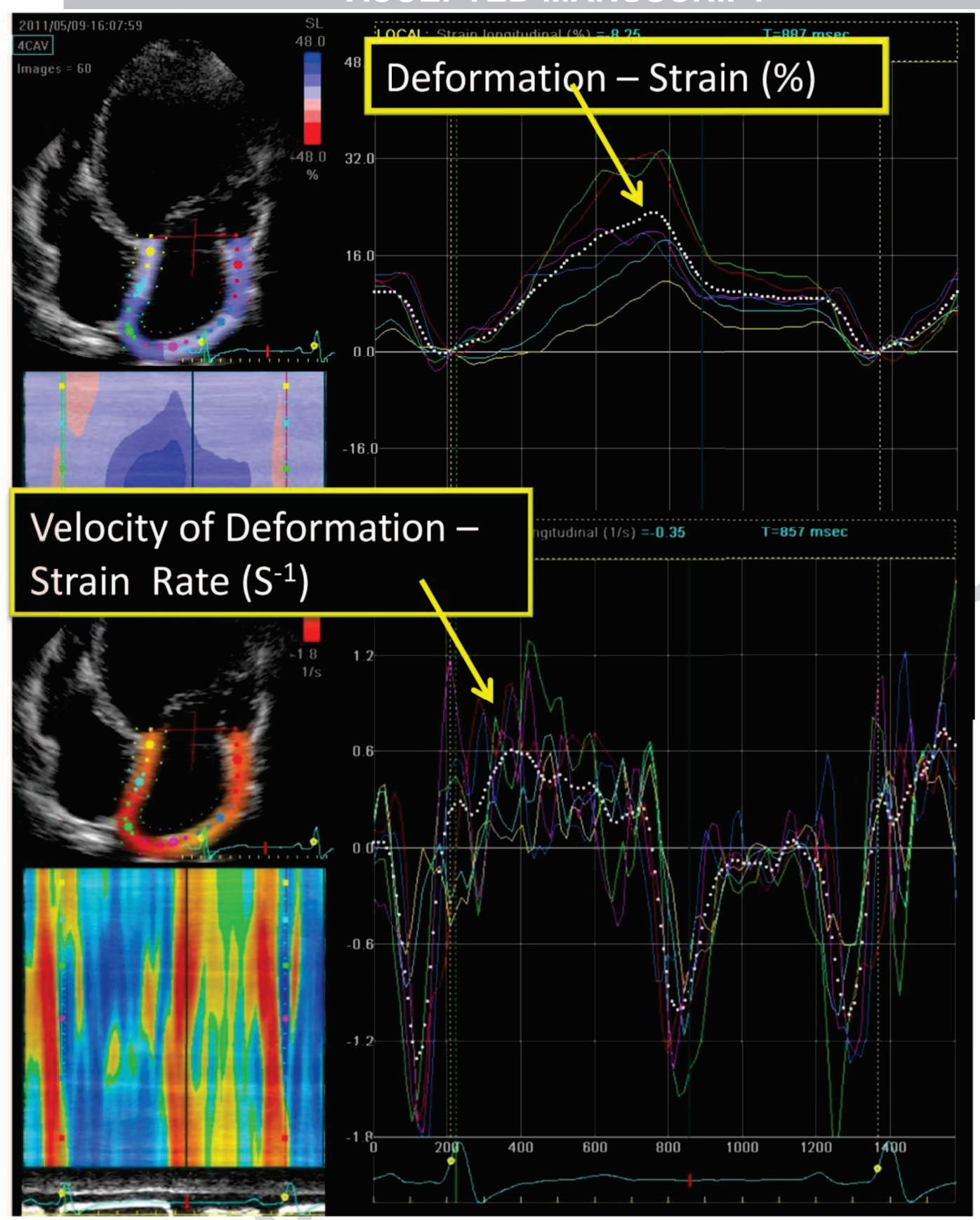

Figure 1: example of left atrial strain and strain rate acquisitions 


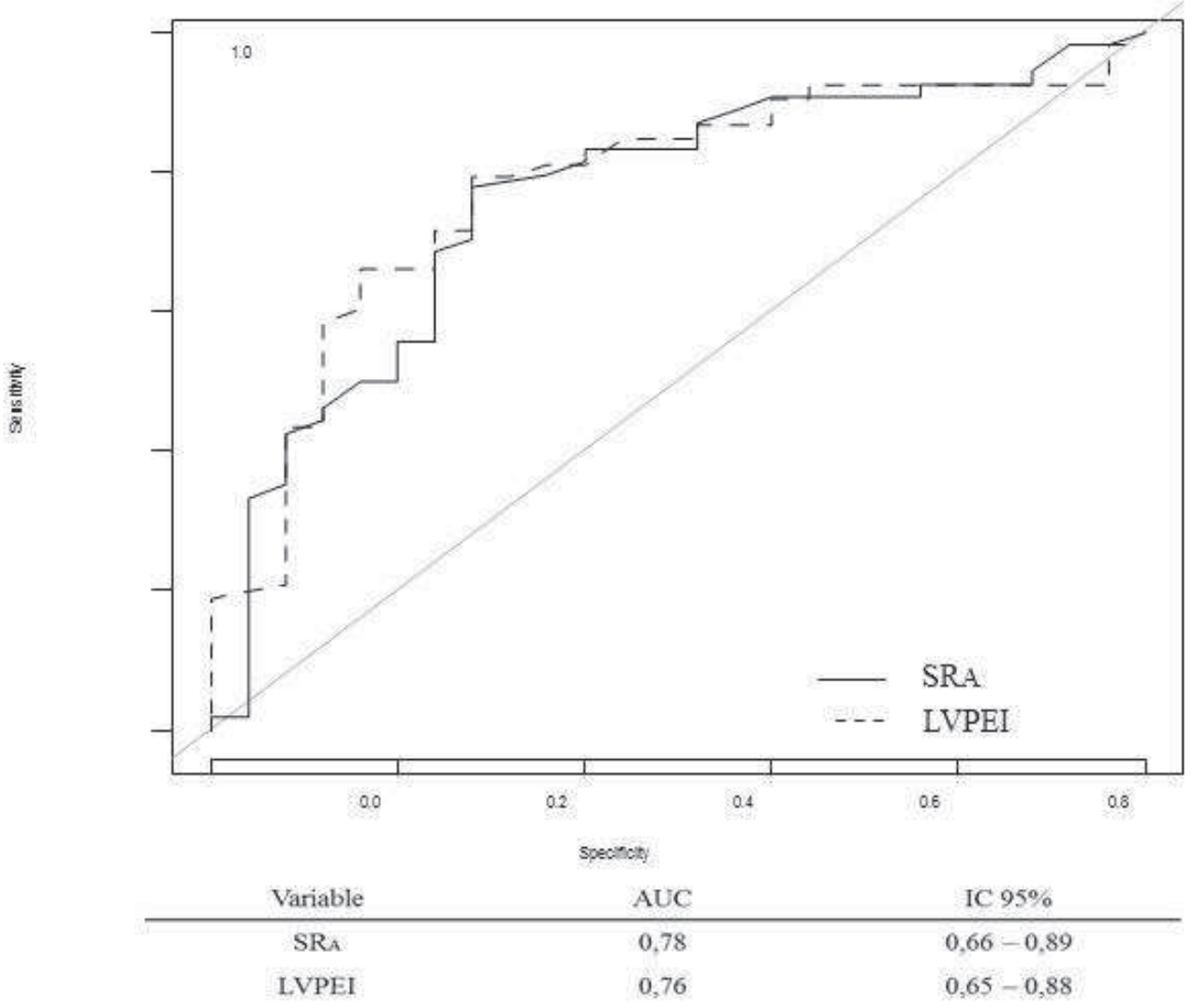

Figure 2: ROC Curve for LVPEI (Left) and SRA and Response to Cardiac Resynchronization Therapy at 6 Months 